\title{
A prospective study of foetomaternal outcome in placenta praevia
}

\author{
Somika Kaul, Bijal Rami*
}

Department of Obstetrics and Gynecology, Government Medical College and S.S.G Hospital, Vadodara, Gujarat, India

Received: 30 July 2019

Accepted: 30 August 2019

\section{*Correspondence:}

Dr. Bijal Rami,

E-mail: bijalrami323@yahoo.com

Copyright: ( ) the author(s), publisher and licensee Medip Academy. This is an open-access article distributed under the terms of the Creative Commons Attribution Non-Commercial License, which permits unrestricted non-commercial use, distribution, and reproduction in any medium, provided the original work is properly cited.

\section{ABSTRACT}

Background: Placenta praevia is one of the serious obstetric problems with far reaching effects and a major cause of antepartum haemorrhage. The aim of the study was to evaluate the foetomaternal outcome of pregnancies with placenta praevia.

Methods: The present study was a prospective case control study conducted in the Department of Obstetrics and Gynaecology, Lal Ded Hospital, Srinagar from August 2009 to October 2010.

Results: Among the 100 cases of placenta praevia studied bleeding per vaginum was the most common presenting symptom. Major placenta praevia was more common (53\%) than minor placenta praevia. $43 \%$ of the cases of placenta praevia delivered before 37 completed weeks as compared to only $6 \%$ in the control group. All cases of placenta praevia delivered by caesarean section. Maternal morbidity in terms of postpartum haemorrhage (32\%), intraoperative bowel and bladder injury (2\%) and intensive care unit admission (1\%) was more in cases of placenta praevia. Foetal complications in terms of neonatal intensive care unit admission (19\%), neonatal death (10\%) and stillbirth (5\%) were more in pregnancies with placenta praevia as compared to controls. $48 \%$ of patients with placenta praevia required transfusion of blood and blood products as compared to $4.5 \%$ among controls.

Conclusions: There is a significant increase in maternal morbidity in pregnancies complicated with placenta praevia. Also, there is a higher incidence of foetal complications and neonatal death. Managing a case of placenta praevia is a challenge in present day obstetrics and it creates a huge burden on the health care system.

Keywords: Antepartum haemorrhage, Caesarean section, Foetal morbidity, Maternal morbidity and mortality, Neonatal intensive care unit admission, Placenta praevia, Postoperative complications

\section{INTRODUCTION}

Antepartum haemorrhage continues to be one of the leading causes of maternal and foetal morbidity and mortality. According to the Royal College of Obstetricians and Gynaecologists antepartum haemorrhage is defined as bleeding from or into the genital tract, occurring from $24^{+0}$ weeks of pregnancy and prior to the birth of the baby. ${ }^{1}$ Placenta praevia and abruptio placenta are the two most important causes of antepartum haemorrhage. $35 \%$ cases of antepartum haemorrhage are due to placenta praevia. $^{2}$
The lack of clinical differentiation between the causes of antepartum haemorrhage was first clarified by Edward Rigby in 1775. Antepartum haemorrhage was placed in two classes by him. One he called as accidental haemorrhage which is due to the premature separation of normally situated placenta and the other unavoidable haemorrhage was soon replaced by the term placenta praevia. $^{3}$

When the placenta is inserted wholly or partially in the lower uterine segment, it is termed as placenta praevia. ${ }^{4}$ Placenta praevia can be graded according to the 
relationship and/or the distance between the lower placental edge and the internal os of the uterine cervix. Grade I or minor praevia is defined as a lower edge inside the lower uterine segment; grade II or marginal praevia as a lower edge reaching the internal os; grade III or partial praevia when the placenta partially covers the cervix; and grade IV or complete praevia when the placenta completely covers the cervix. Grade I and II are also often defined as 'minor' placenta praevia whereas grades III and IV are referred to as 'major' placenta praevia. ${ }^{5}$ The incidence of placenta praevia average 0.3 percent or 1 case per 300 to 400 deliveries. $^{6}$

The most characteristic event in placenta praevia is painless haemorrhage, which usually does not appear until the end of second trimester or after. Most of the patients present with third trimester bleeding. In order to localise placenta in these cases of antepartum haemorrhage ultrasound is the imaging modality of choice. With the better availability of antenatal ultrasound most patients are now detected antenatally before the onset of significant bleeding. ${ }^{7}$

The major causes of maternal mortality and morbidity in a case of placenta praevia are haemorrhage, anaemia, sepsis and placenta accrete or one of its more advanced forms4. Some patients may succumb to haemorrhage leading to shock and renal failure. In addition to maternal complications stated above placenta praevia has many adverse effects on the foetus as well. Foetal complications include prematurity, low birth weight, birth asphyxia and intrauterine death. ${ }^{8}$ Overall, perinatal mortality ranges between $4-8 \% .{ }^{4} \mathrm{Up}$ to one-fifth of verypreterm babies are born in association with antepartum haemorrhage and the known association of antepartum haemorrhage with cerebral palsy can be explained by preterm delivery. ${ }^{1}$

In view of the above discussion authors see placenta praevia as one of the major causes of maternal and foetal morbidity and mortality. This study is conducted to know clinical presentations, foetomaternal outcome and complications in cases of placenta praevia.

\section{METHODS}

The present study is a prospective case control study conducted in the Department of Obstetrics and Gynaecology, Lalla Ded Hospital, Srinagar. The study was conducted from August 2009 to October 2010, in which 100 patients with ultrasound documented placenta praevia served as cases and 200 patients not having placenta praevia were taken as controls.

\section{Inclusion criteria}

- Pregnant women at or more than 30 weeks of gestation who had ultrasound documented placenta praevia, irrespective of their parity and between the age of 20 to 40 years, coming to emergency department or admitted in antenatal ward were included in the study.

\section{Exclusion criteria}

- All the pregnant women presenting with bleeding per vaginum or low-lying placenta before 30 weeks of gestation

- Antepartum haemorrhage due to abruptio placentae or any other local cause

- Pregnancy complicated with other medical disorders like hypertension, diabetes mellitus and thyroid disorders.

The After taking an informed consent, a detailed history and general physical examination was conducted in each patient. All the patients were subjected to the routine investigations like haemoglobin, clotting time, bleeding time, platelet count and blood group. Ultrasound findings of all the patients were noted down. A record was made of the mode of delivery, intra-operative and postoperative complications and the gestational age at the time of delivery. An enquiry was made about the number of blood transfusions each patient received. The number of days of hospital stay was also recorded. Maternal and foetal mortality was also assessed. Both mother and baby were followed up for one week after delivery.

\section{Statistical analysis}

The data obtained was analysed statistically and all the $\mathrm{p}$ valves $<0.05$ were taken as significant.

\section{RESULTS}

This prospective study was carried out on 300 women, of which 100 patients of ultrasound documented placenta praevia formed the study group and 200 patients not having placenta praevia were taken as controls. $91 \%$ of patients in the study group presented with vaginal bleeding, while as $83.5 \%$ of patients in the control group presented with labour pains. The percentage of patients in the control group that were admitted for post-dated pregnancy and decreased foetal movements was $4 \%$ each (Table 1). So, authors noted that vaginal bleeding was the single most common presenting symptom in patients with placenta praevia.

Table 1: Presenting symptom at the time of admission.

\begin{tabular}{|lllll|}
\hline \multirow{2}{*}{ Presentation } & Study & \multicolumn{3}{c|}{ Control } \\
\hline Bleeding per vaginum & n & \% & n & \% \\
\hline Routine admission & 91 & 91 & 0 & 0.0 \\
\hline Labour pains & 9 & 9.0 & 25 & 12.5 \\
\hline Post dated pregnancy & 0 & 0.0 & 167 & 83.5 \\
\hline $\begin{array}{l}\text { Decreased foetal } \\
\text { movements }\end{array}$ & 0 & 0.0 & 4 & 2.0 \\
\hline
\end{tabular}


Out of 100 patients in the study group 53 had major placenta praevia and 47 had minor placenta praevia (Table 2).

Table 2: Type of placenta praevia in cases.

\begin{tabular}{|lll|}
\hline Type of placenta praevia & n & $\%$ \\
\hline Major & 57 & 57 \\
\hline Minor & 43 & 43 \\
\hline
\end{tabular}

In the study group $16 \%$ of patients had to be delivered before 34 weeks of gestation, while as the percentage was only $2.5 \%$ in the control group. Out of 100 patients in the study group $57 \%$ delivered at or after 37 weeks of gestation as against a huge percentage of $94 \%$ in the control group (Table 3). The results were statistically significant, and authors found that patients with placenta praevia delivered at a much lower gestational age.

Table 3: Gestational age at the time of termination of pregnancy.

\begin{tabular}{|lll|}
\hline Gestational age (weeks) & Study & Control \\
\hline 30 weeks to 33 weeks 6 days & 16.0 & 2.5 \\
\hline 34 weeks to 36 weeks 6 days & 27.0 & 3.5 \\
\hline$\geq 37$ weeks & 57.0 & 94 \\
\hline Mean \pm SD & $35.8 \pm 2.1$ & $38.0 \pm 1.5$ \\
\hline
\end{tabular}

All the patients in the study group had to be delivered by caesarean section, while as only $45 \%$ of the controls required a caesarean section (Table 4 ).

Table 4: Mode of delivery in patients of study and control group.

\begin{tabular}{|c|c|c|c|c|c|c|}
\hline & & \multicolumn{2}{|c|}{ Study } & \multicolumn{2}{|c|}{ Control } & p Value \\
\hline \multirow{4}{*}{ Mode of delivery } & & $\mathrm{n}$ & $\%$ & $\mathrm{n}$ & $\%$ & \multirow{4}{*}{0.000 (Sig) } \\
\hline & Normal vaginal & 0 & 0.0 & 106 & 53.0 & \\
\hline & Instrumental vaginal & 0 & 0.0 & 4 & 2.0 & \\
\hline & Caesarean section & 100 & 100.0 & 90 & 45.0 & \\
\hline
\end{tabular}

Table 5: Incidence of intraoperative and postoperative complications in the study and control group.

\begin{tabular}{|llllll|}
\hline Intra-operative and post-operative complications & \multicolumn{3}{c|}{ Control } & p value \\
\hline Placenta accreta & n & \% & n & \% & \\
\hline Placenta percreta & 7 & 7.0 & 0 & 0.0 & 0.000 (Sig) \\
\hline Placenta increta & 0 & 0.0 & 0 & 0.0 & \\
\hline Bowel or bladder damage & 1 & 1.0 & 0 & 0.0 & $0.157(\mathrm{NS})$ \\
\hline Caesarean hysterectomy & 2 & 2.0 & 0 & 0.0 & $0.045(\mathrm{Sig})$ \\
\hline Retroperitoneal haematoma & 5 & 5.0 & 0 & 0.0 & 0.001 (Sig) \\
\hline Post-partum haemorrhage & 0 & 0.0 & 0 & 0.0 & \\
\hline Postoperative complications & 32 & 32.0 & 9 & 4.5 & $0.000(\mathrm{Sig})$ \\
\hline
\end{tabular}

Table 6: Foetal and maternal outcome in the study and control group (one week follow up).

\begin{tabular}{|c|c|c|c|c|c|c|}
\hline & & Stu & oup & & oup & p value \\
\hline & & $\mathbf{n}$ & $\%$ & $\mathbf{n}$ & $\%$ & \\
\hline Foetal & Admitted in neonatal intensive care unit & 19 & 19.0 & 8 & 4.0 & \\
\hline mortality and & Expired & 10 & 10.0 & 2 & 1.0 & 0.000 (S1g) \\
\hline morbidity & Born dead & 5 & 5.0 & 8 & 4.0 & \\
\hline Maternal mort & lity & 0 & 0.0 & 0 & 0.0 & \\
\hline
\end{tabular}

Table 7: Incidence of transfusion of blood and blood products.

\begin{tabular}{|lllll|}
\hline Group & n & $\%$ & Maximum number of transfusions received by a patient & p value \\
\hline Study & 48 & 48.0 & 12 & 0.000 (Sig) \\
\hline Control & 9 & 4.5 & 3 & \\
\hline
\end{tabular}

Table 5 shows the intra-operative and postoperative complications in the study and control group. Among 100 patients of placenta praevia $7 \%$ had placenta accrete, $1 \%$ had placenta increta and $2 \%$ developed bowel or bladder injuries intra-operatively. $5 \%$ of the patients required an obstetric hysterectomy. As against $32 \%$ of cases only 
$4.5 \%$ of the controls developed postpartum haemorrhage. Only one patient in the study group required intensive care unit admission.

As depicted in Table 6, 19\% of the babies born to mothers in the study group were still admitted in the neonatal intensive care unit after a follow up of one week, as against $4 \%$ in the control group. $10 \%$ of the babies born to the mothers in the study group expired over a follow up of one week as compared to only $1 \%$ in the control group. $5 \%$ of the babies born to mothers in the study group were born dead. There was no maternal mortality in either of the groups.

Almost half (48\%) of the patients in the study group received transfusion of blood and blood products as against $4.5 \%$ in the control group. Maximum number of transfusions received by a patient in the study and control group was 12 and 3 respectively (Table 7).

Table 8: Haemoglobin levels on second day of delivery (g\%).

\begin{tabular}{|llc|}
\hline Group & Mean \pm SD & p value \\
\hline Study & $8.2 \pm 1.5$ & \multirow{2}{*}{$0.000(\mathrm{Sig})$} \\
\hline Control & $9.0 \pm 1.0$ & \\
\hline
\end{tabular}

Authors subjected all the patients to postoperative haemoglobin level on second postoperative day. The mean haemoglobin level in the study and the control group was $8.2 \mathrm{~g} \%$ and $9 \mathrm{~g} \%$ respectively (Table 8 ). Thus, patients in the study group had a lower level of postoperative haemoglobin as compared to control group and the difference was statistically significant.

Table 9: Hospital stay (in days).

\begin{tabular}{|lll|}
\hline Group & Mean \pm SD & p value \\
\hline Study & $11.2 \pm 6.0$ & \multirow{2}{*}{$0.000(\mathrm{Sig})$} \\
\hline Control & $3.9 \pm 3.0$ & \\
\hline
\end{tabular}

As shown in Table 9, the average number of days of hospital stay was 11.2 days in the study group and 3.9 days in the control group. Maximum number of days of hospital stay for a patient was 38 and 14 in the study and control group respectively.

\section{DISCUSSION}

Placenta praevia continues to be one of the important causes of maternal and foetal mortality and morbidity. The present study is done to evaluate the foetomaternal outcome in placenta praevia.

Bleeding per vaginum was presenting symptom in majority of the patients in the study group (91\%). The results were similar to that obtained by McShane PM et al, where more than half of the patients presented with bleeding before 36 weeks with one third of the patients having their first episode before 30 weeks. ${ }^{9}$ In a study done by Sarojini et al, $32 \%$ of patients were admitted with history of bleeding per vagina and $24.5 \%$ developed bleeding after admission to the hospital. ${ }^{10}$

In the present study, 53\% of patients had major placenta praevia while as $47 \%$ had minor praevia. Similarly, according to Sarojini et al. $60.4 \%$ of the cases were having major placenta praevia. ${ }^{10}$ In a study done by Farhat Nasreen, $64 \%$ of patients were having major placenta praevia and $36 \%$ were minor placenta praevia. ${ }^{11}$

In the present study, authors compared the gestational age at the time of delivery in both the study and control group and found that $43 \%$ of patients in the study group delivered before 37 completed weeks as compared to $6 \%$ in the control group. As compared to $27 \%$ of the cases only $3.5 \%$ of the controls delivered between 34 to 37 weeks. According to the study done by Sarojini et al, $12.3 \%$ cases delivered prior to 32 weeks, $27.4 \%$ delivered between 32 to 37 weeks and $64 \%$ cases delivered after 37 completed weeks. ${ }^{10}$ The results of the present study are consistent with that done by Saeed $\mathrm{Z}$ et al. They observed that gestational age at the time of termination of pregnancy by caesarean section was 37 weeks or more in $56 \%$ of the patients, between $34-37$ weeks in $30 \%$ of the patients and $28-34$ weeks in $14 \%$ of patients. ${ }^{12}$

Authors also compared the study and control group on the basis of mode of delivery. $100 \%$ of patients in the study group underwent caesarean section while as among controls only $45 \%$ required a caesarean section. In the study done by Sarojini et al, $85.8 \%$ of cases underwent caesarean delivery. ${ }^{10}$ The results of present study are consistent with those obtained by Saeed $\mathrm{Z}$ et al in which all the 50 patients of placenta praevia studied required delivery by caesarean section. ${ }^{12}$

In our study authors observed and followed all the patients till one week and noted all the intra-operative and postoperative complications. The most frequently encountered complication was postpartum haemorrhage, seen in $32 \%$ of the patients in the study group. Postpartum haemorrhage occurring in these patients was initially managed conservatively however $5 \%$ required caesarean hysterectomy. On the contrary, only $4.5 \%$ of patients in the control group developed postpartum haemorrhage. The frequency of bowel and bladder injury was $2 \%$ in the study group while as no patient developed such complication in the control group. No patient either in the study and the control group developed retroperitoneal hematoma. Placenta accrete was present in $7 \%$ of patients in the study group and one patient had placenta increta. In the present study, 1 out of 100 patients of placenta praevia required intensive care unit admission in the post-operative period. No patient underwent re-exploratory laparotomy. In a similar study done by Dhanalaxmi KR, postpartum haemorrhage was seen in $21.43 \%$ of cases, $2.38 \%$ cases went into acute renal failure, $3 \%$ developed pneumonia, 2 cases had 
wound gaping and one patient had relaparotomy13. In the study done by Saeed $\mathrm{Z}$ et al, postpartum haemorrhage occurred in $38 \%$ of patients, out of which $4 \%$ required caesarean hysterectomy. Bowel and bladder injury occurred in $2 \%$ of patients. One patient developed retroperitoneal haematoma. Placenta accrete was present in $8 \%$ of patients and $2 \%$ had placenta percreta. $4 \%$ patients required intensive care unit admission postoperatively. Out of the 50 studied patients by Saeed Z et al, one developed septicaemia and one required reexploratory laparotomy. ${ }^{12}$

In the present study, $19 \%$ of the babies born to mothers in the study group were still admitted in the neonatal intensive care unit after one week follow up as compared to $4 \%$ babies born to mothers in the control group. In the study group, $5 \%$ of the babies were born dead while $10 \%$ expired over a follow up of one week. Compared to this, $4 \%$ of the babies born to patients in the control group were born dead and $1 \%$ expired over a one week follow up. No maternal death was reported either in the study group or in the control group. In the study done by Sarojini et al, $30.2 \%$ of the babies were admitted to the neonatal intensive care unit, $7.5 \%$ were stillborn, $14.2 \%$ were early neonatal deaths and $1.9 \%$ babies were born with congenital anomalies. ${ }^{10}$ In another study done by Kaur $\mathrm{K}$ et al on 48 cases of placenta praevia in scarred uterus, $6.25 \%$ of babies were stillborn and $14.58 \%$ were neonatal deaths. ${ }^{14}$ In a similar study done by Saeed $\mathrm{Z}$ et al, neonatal mortality was $14 \%$ and a maternal mortality of $2 \%$ was reported. ${ }^{12}$

Authors also made a note of the number of patients in the study and control group who received transfusion of blood or blood products. Nearly half of the patients in the study group received blood transfusion as compared to only $4.5 \%$ in the control group. In the study done by Kaur $\mathrm{K}$ et al, about $70 \%$ of the patients required blood transfusion. ${ }^{14}$ Similarly, in a study done by Khirasaria $\mathrm{DM}$ et al, $86 \%$ of the cases required blood transfusion. ${ }^{15}$ In another study done by Saeed $\mathrm{Z}$ et al. $50 \%$ of the patients required one or two blood transfusions. ${ }^{12}$

When all patients in both the groups were subjected to post-operative haemoglobin on second postpartum day, the mean haemoglobin level in the study and control group was $8.2 \mathrm{~g} \%$ and $9 \mathrm{~g} \%$ respectively. This observation is consistent with that made by Saeed $\mathrm{Z}$ et al, in their study, which showed that $46 \%$ of the patients with placenta praevia developed anaemia post operatively. ${ }^{12}$ Sheiner E et al, found that pregnancies associated with placenta praevia had a significantly higher rate of postpartum anaemia as compared to pregnancies without placenta praevia. ${ }^{16}$

Authors studied the average number of days of hospital stay in both the groups. Mean number of days of hospital stay in patients of the study group were 11.2 days as compared to 3.9 days in the control group. As reported by Saeed $\mathrm{Z}$ et al, in their study, maximum number of patients of placenta praevia were discharged after 7-9 days of stay in the hoapital. ${ }^{12}$ Sheiner E et al, also found that in pregnancies complicated with placenta praevia there was a prolonged stay of mother and baby in the hospital. ${ }^{16}$

\section{CONCLUSION}

From the above observations following conclusions were drawn. Major placenta praevia is more common than minor placenta praevia. The patients with placenta praevia are at a higher risk of preterm delivery and have a much greater chance of being delivered by a caesarean section. While as such patients are more likely to develop postpartum haemorrhage and intraoperative bowel and bladder injury, there is a greater chance of them requiring an intensive care support as compared to those not having placenta praevia. The babies born to patients of placenta praevia not only have more chances of neonatal intensive care unit admission but also higher likelihood of stillbirth and neonatal death. Having placenta praevia increases the risk of developing postoperative anaemia and also there is higher chance of such a patient receiving blood transfusion. Also, patients of placenta praevia have a prolonged hospital stay. Thus, to conclude placenta praevia significantly increases the maternal morbidity and foetal morbidity and mortality. This emphasises the need for regular antenatal care, so as to segregate such highrisk patients for delivery at a centre with facilities for management of possible maternal and foetal complications.

Funding: No funding sources

Conflict of interest: None declared

Ethical approval: Not required

\section{REFERENCES}

1. Royal College of Obstetricians and Gynaecologists. Antepartum Haemorrhage: Green top guidelines No. 63, 2011. Available at: rcog.org.uk/globalassets/documents/guidelines/gtg_63.p df.

2. Sheikh F, Khokhar S. A study of antepartum haemorrhage: maternal and perinatal outcome. Med Chan. 2010;16:22.

3. Baskett TF. Edward Rigby (1747-1821) of Norwich and his essay on the uterine haemorrhage. J Royal Society Med. 2002;95(12):618-22.

4. Gupta B, Mishra, R. Antepartum Haemorrhage. In: Mishra R, eds. Ian Donald's practical obstetric problems. $7^{\text {th }}$ ed. Wolters Kluwer. 2014:315-38.

5. Jauniaux ERM, Alfirevic Z, Bhide AG, Belfort MA, Burton GJ, Collins SL, et al. Royal College of Obstetricians and Gynaecologist: Placenta Praevia and Placenta Accreta: Diagnosis and Management. Green-top Guideline No 27 a, 2018. Br J Obstet Gynaecol. 2018:e10.

6. Obstetrical Hemorrhage. In: Cunningham FG, Leveno KJ, Bloom SL, Spong CY, Dashe JS, 
Hoffman BL, et al. eds. Williams obstetrics. $24^{\text {th }}$ ed. McGraw-Hill; 2014:780-828.

7. Saeed Z, Ikram M, Tazian S. Placenta praevia; etiology and fetomaternal outcome. Prof Med J. 2009;16(1):139-44.

8. Rangaswamy H, Govindaraju K. Fetomaternal outcome in placenta praevia- a retrospective study in teaching hospital. Int $\mathbf{J}$ Repro Contra Obstet Gynaecol. 2016;5(9):3081-4.

9. McShane PM, Heyl PS, Epstein MF. Maternal and perinatal morbidity resulting from placenta praevia. Obstet Gynecol. 1985;65(2):176-82.

10. Sarojini, Malini KV, Radhika. Placenta praevia and its effect on marenal health and fetal outcome. Int $\mathbf{J}$ Reprod Contracept Obstet Gynecol. 2016;5(10):3496-9.

11. Nasreen F. Incidence causes and outcome of placenta praevia. J Post Med Inst. 2016;17(1):99-104.

12. Saeed Z, Ikram M, Tazian S. Placenta praevia; etiology and fetomaternal outcome. Prof Med J. 2009;16(1):139-44.
13. Dhanalaxmi KR. Clinical features and course of pregnancy in placenta praevia. Int $\mathbf{J}$ Reprod Contracept Obstet Gynecol. 2016;5(6):2000-4.

14. Kaur K, Kaur A, Garg R. Fetomaternal outcome in placenta praevia in scarred uterus. Int J Cur Res Med Sci. 2017;3(8):52-37.

15. Khirasaria DM, Nayak TC. A study of complications in cases of placenta praevia. Int J Contracept Obstet Gynecol. 2017;6(12):5503-7.

16. Sheiner E, Vardi IS, Hallak M. Placenta praevia: obstetric risk factors and pregnancy outcome. J Mat Foetal Med. 2001;10(6):414-9.

Cite this article as: Kaul S, Rami B. A prospective study of foetomaternal outcome in placenta praevia. Int J Reprod Contracept Obstet Gynecol 2019;8:4028-33 